\title{
Genetic Diversity Assessment of Rarely Cultivated Traditional Indica Rice (Oryza sativa L.) Varieties
}

\author{
T. Rekha, ${ }^{1}$ Kottackal Poulose Martin, ${ }^{1}$ V. B. Sreekumar, ${ }^{2}$ and Joseph Madassery ${ }^{1}$ \\ ${ }^{1}$ Department of Biotechnology, Calicut University, Kerala 673 635, India \\ ${ }^{2}$ Forest Ecology and Biodiversity Conservation Division, Kerala Forest Research Institute, Kerala, Thrissur 680 653, India
}

Correspondence should be addressed to Kottackal Poulose Martin, marttinet@yahoo.com and

Joseph Madassery, madasseryjoseph@yahoo.com

Received 14 February 2011; Revised 30 March 2011; Accepted 10 May 2011

Academic Editor: Sneh Singla-Pareek

Copyright (C) 2011 T. Rekha et al. This is an open access article distributed under the Creative Commons Attribution License, which permits unrestricted use, distribution, and reproduction in any medium, provided the original work is properly cited.

\begin{abstract}
Random amplified polymorphic DNA fingerprinting was performed to assess the genetic diversity among rarely cultivated traditional indica rice (Oryza sativa L.) varieties collected from a tribal hamlet of Kerala State, India. A total of 664 DNA bands amplified by 15 primers exhibited $72.9 \%$ polymorphism (an average of 32.3 polymorphic bands per primer). The varieties Jeerakasala and Kalladiyaran exhibited the highest percent (50.19\%) polymorphism, while Thondi and Adukkan showed the lowest (9.85\%). Adukkan (78 bands) and Jeerakasala (56 bands) yielded the highest and the lowest number of amplicons, respectively. Unweighted Pair Group Method with Arithmetic mean analysis using the Dice similarity coefficient showed the highest value of similarity coefficient between the varieties Adukkan and Thondi, both shared higher level of similarity (0.81), followed by Kanali and Thondi (0.88). Of the three subclusters, the varieties of Adukkan, Thondi, Kanali, Mannuveliyan, Thonnuranthondi, and Chennellu grouped together with a similarity of 0.77 . The second group represented by Navara, Gandhakasala, and Jeerakasala with a similarity coefficient of 0.76 formed a cohesive group. The variety Kalladiyaran formed an isolated position that joined the second cluster. The Principal Coordinate Analysis also showed separation of Kalladiyaran from the other varieties.
\end{abstract}

\section{Introduction}

Traditional rice varieties with high genetic variation overwhelmingly support the improvement of rice. India, rich in diversity of indica varieties of rice, accounts for approximately $80 \%$ of the cultivated rice. Indian rice varieties are evolved through traditional selection, hybridisation, and back crossing with locally adapted high yielding lines. Kerala, one of the states of India, with more than 300 hundred traditional rice varieties including scented and medicinal varieties contributes much variation to India's bowl of rice diversity. Wayanad District of Kerala (http://www.wayanad.nic.in; http://en.wikipedia.org/wiki/Wayanad_district), boarded by the Western Ghats, is a settlement of several tribal groups with 75 traditional rice varieties adaptable to biotic and abiotic stresses (http://www.mssrf.org/iec/pubfile/Virtual\% 20Congress_2009.pdf). The promising traditional rice varieties which are rare in cultivation, collected from the tribal areas for the present studies, are Adukkan, Thondi, Kanali, Mannuveliyan, Thonnuranthondi, Chennellu, Kalladiyaran, Jeerakasala (Aromatic), Gandhakasala, (Aromatic), and Navara black-awned (Medicinal), and the salient features are given in Table 1. Of which, the scented and medicinal rice varieties are peculiar in having high market value. The varieties Mannuveliyan, Thonnuranthondi, Thondi, Chennellu, Jeerakasala, and Gandhakasala are cultivated presently by Kurumas, a tribal group, to meet their nutritive, social, and ritual needs. Jeerakasala and Gandhakasala, are traditional scented rice varieties which experienced an overlook because of the overemphasis on Basmati. Thondi and Mannuveliyan are highly preferred because of their nutritive and fodder value. The variety Navara, considered as "God's precious gift," is an upland traditional rice variety unique to Kerala because of its great ayurvedic use since early centuries (http://www.pakkam.se/ Project_in_Brief_Scannad.pdf). In the case of Navara, due to 
TABLE 1: Salient features of the rice varieties used in the present study.

\begin{tabular}{lcccc}
\hline Varieties (abbreviations) & Growth duration (days) & Plant height $(\mathrm{cm})$ & Grain characters & Weight per grain $(\mathrm{mg})$ \\
\hline Navara (NV) & $68-90$ & 50 & $60 \mathrm{~mm}$ long light red grains & 18.4 \\
Gandhakasala (GS) & $150-180$ & 68 & $40 \mathrm{~mm}$ small white grains & 12.4 \\
Jeerakasala (JS) & $150-180$ & 72 & $40 \mathrm{~mm}$ small white grains & 13.3 \\
Adukkan (AU) & $160-165$ & 65 & $50 \mathrm{~mm}$ long reddish, round grains & 23 \\
Thondi (TD) & $160-165$ & 50 & $50 \mathrm{~mm}$ long reddish, round grains & 24.3 \\
Kanali (KL) & $180-190$ & 30 & $50 \mathrm{~mm}$ long reddish, round grains & 25 \\
Mannuveliyan (MV) & $160-165$ & 48 & $50 \mathrm{~mm}$ long reddish, round grains & 25 \\
Thonnuranthondi (TT) & $160-165$ & 40 & $50 \mathrm{~mm}$ long reddish, round grains & 27 \\
Chennellu (CN) & $120-150$ & 50 & $50 \mathrm{~mm}$ long reddish, round grains & 28 \\
Kalladiyaran* (KY) & $100-150$ & 30 & $50 \mathrm{~mm}$ long reddish, round grains & 22 \\
\hline
\end{tabular}

Wt per grain was an average of 20 grains.

*Highly endangered.

the lack of cultivation in large scale, it is difficult to get seeds, are costly, that is, $\sim 15$ times per $\mathrm{Kg}$ than other rice varieties (http://navara.in/index.html). The vernacular names such as Kalladiyaran, Kanali, Mannuveliyan, and Thondi. point to the drought tolerant nature. Kalladiyaran is enlisted as the highly endangered rice. These traditional varieties at the brim of extinction serve as donors of genes governing specific traits such as disease (gall-midge, bacterial resistance) and drought resistance for the improvement of the crop. However, due to high fascination of hybrid varieties, the traditional varieties with desirable traits were neglected and are now rare in cultivation. A high turnout to hybrid varieties as a consequence of green revolution resulted in an erosion of traditional varieties/landraces, which narrowed down the varietal diversity. As a proof, pedigree of 29 rice varieties, developed through recombination breeding, released in Kerala State between 1966 and 1995 revealed a narrow genetic base, with only 37 ancestors [1].

The exploitation of plant genetic resources requires a detailed knowledge of the amount of genetic variation that exists within the species [2]. Molecular markers, enabling the detection of differences in the genetic information carried out by the different individuals, are highly useful to assess and exploit the genetic variability for crop improvement programmes. Molecular markers serve as a valuable tool to assess the genetic variation, varietal classification, and germplasm identification of rice [3-6]. Of the different molecular markers, RAPD, in which random fragments of DNA are amplified from DNA samples using short, arbitrary primers, is highly preferred because of its simplicity, low cost and less performing time, and also because no prior knowledge on the genotype is required. Assessment of genetic diversity in cultivated indica rice varieties by RAPD has been documented [6-9]. RAPD markers have been exploited to tag several resistance genes [10-14]. The use of genes retrieved from the highly adapted local traditional varieties, even if it is low yielding, to the high yielding varieties with low adaptability enables making up the plants suitable to the microclimate befitting to the region. The rice varieties of the present study possessing important agronomic characters such as drought and disease resistance are hitherto not assessed genetically. Thus, the present study analyses the genetic diversity among ten traditional rarely cultivated rice varieties collected from the tribal hamlet of Kerala State, India using RAPD fingerprinting.

\section{Materials and Methods}

2.1. Rice Varieties. Ten rarely cultivated traditional varieties of rice, namely, Navara, Gandhakasala, Jeerakasala, Mannuveliyan, Kanali, Thondi, Thonnuranthondi, Kalladiyaran, Chennellu, and Adukkan collected from the farmers of the tribal regions of Wayanad District (http://www .wayanad.nic.in; http://en.wikipedia.org/wiki/Wayanad_district, Kerala, India, were used for the present study (Table 1).

2.2. DNA Extraction and RAPD Analysis. Seedlings of all the rice varieties grown in the greenhouse of the Department of Biotechnology, University of Calicut, were used for the extraction of DNA. DNA was extracted individually from each variety using the method of Dellaporta et al. [15] with $2 \%(\mathrm{v} / \mathrm{v}) \beta$-mercaptoethanol (added just before use) and $2 \%(\mathrm{w} / \mathrm{v})$ polyvinylpyrrolidone. The purity was examined by agarose $(0.8 \%)$ gel electrophoresis, and the concentration of DNA was determined by UV-visible spectrophotometer (UV-1601, Shimadzu, Japan). RAPD profiling was performed using 15 primers (OPA-02, OPA-04, OPA-19, OPB01, OPB-04, OPB-20, OPD-08, OPD-16, OPM-06, OPX-04, OPZ-02, OPAA-07, OPAB-02, CB-1, and CB-2) purchased from Integrated DNA Technologies Inc, USA.

PCR reactions were performed in $25 \mu \mathrm{l}$ volume containing 1X Taq buffer, $3 \mathrm{~mm} \mathrm{MgCl}_{2}, 250 \mu \mathrm{M}$ of each dNTPs, $0.2 \mathrm{~nm}$ primer, $100 \mathrm{ng}$ genomic DNA, and 2 units of Taq polymerase (BioGene, USA) using MJ Research Minicycler. The cycling conditions consist of 1 cycle of $94^{\circ} \mathrm{C}$ for $5 \mathrm{~min}$ (initial denaturation), followed by 45 cycles of $94^{\circ} \mathrm{C}$ for $30 \mathrm{sec}$ (denaturation), $35^{\circ} \mathrm{C}$ for $1 \mathrm{~min}$ (annealing), and $72^{\circ} \mathrm{C}$ for $2 \mathrm{~min}$ (polymerisation), with a final extension of $7 \mathrm{~min}$ at $72^{\circ} \mathrm{C}$. A negative control without the rice genomic DNA was kept for amplification along with each primer to check the quality of the primer and to avoid the possibilities of contaminations and primer dimers. The amplification products $(10 \mu \mathrm{l})$ were loaded in an ethidium bromide 
added agarose gel (1.2\%) for electrophoresis (at $125 \mathrm{~V}$ ) in $1 \mathrm{X}$ tris-boric acid-EDTA buffer. The electropherograms were documented using gel AlphaImager documentation analysis system (Alpha Innotech, USA). DNA bands were compared with 500 and $100 \mathrm{bp}$ DNA standard markers (BioGene, USA). The amplifications were performed twice with genomic DNA isolated independently to confirm the reproducibility.

2.3. Data Analysis. The positive amplicons were treated as separate characters and scored for the presence (1) or absence (0) of bands. Polymorphism Information Content (PIC) was calculated based on the number of bands/primer, using the formula PIC $=1-P i 2$, where $P i$ is the frequency of the $i$ th band.

Cluster analysis and Principal Coordinate Analysis (PCO) were carried out in NTSYS (Numerical Taxonomy and Multivariate Analysis System) version 2.01i. Genetic similarities based on Dice coefficient [16] were calculated among all possible pairs using the SIMQUAL option and ordered in a similarity matrix. A dendrogram was constructed by using UPGMA (Unweighted Pair Group Method with Arithmetic mean) [17] to group individual into discrete clusters. Cophenetic correlation was calculated to measure goodness of fit. PCO was performed using the following modules of the NTSYS program: STAND, SIMINT, DECENTER, and EIGEN to identify the number of groups based on Eigen vectors. Two-dimensional ordination provided an additional representation of genetic relationships among the individuals of populations.

\section{Results}

Genetic relationship of 10 traditional rice varieties of Wayanad Dist. studied using 15 RAPD primers produced a total of 664 reproducible DNA bands with an average of 44.3 DNA bands per primer. Their sizes ranged between 2676 (OPB-04) and $110 \mathrm{bp}$ (OPX-04). All the primers displayed polymorphic amplicons (Table 2). Of the total amplicons, $484(72.9 \%)$ were polymorphic for one or more varieties, with an average of 32.3 bands per primer. The remaining $180(27.1 \%)$ bands of the total 664 bands were detected in all varieties. The highest (84) and lowest (2) numbers of amplicons were generated by OPB-04 and OPZ-02, respectively (Table 2 ). The percentage of polymorphism varied with each primer (Table 2). Except the primers OPA-04, OPA-19, and OPD-16, all others exhibited more than 50\% polymorphism (Table 2), reaching 100\% for OPB-01, OPB-04, OPZ-02, OPAA-07, OPAB-02, OPA-02, OPD-08, OPM-6, and CB-2 primers (Table 2; Figure 1). Several primers displayed $100 \%$ polymorphism between the varieties. Similarly, between varieties, many primers showed no polymorphism. On primer basis, the polymorphism was the lowest between Thondi and Kanali (4.8\%) against the primer OPB-04 and was followed by the same varieties (5.2\%) against OPX-04. The polymorphism between Adukkan and Kanali (5.3\%) was similar against OPX-04. Among the varieties, Jeerakasala and Kalladiyaran exhibited the highest mean percent (50.19\%)

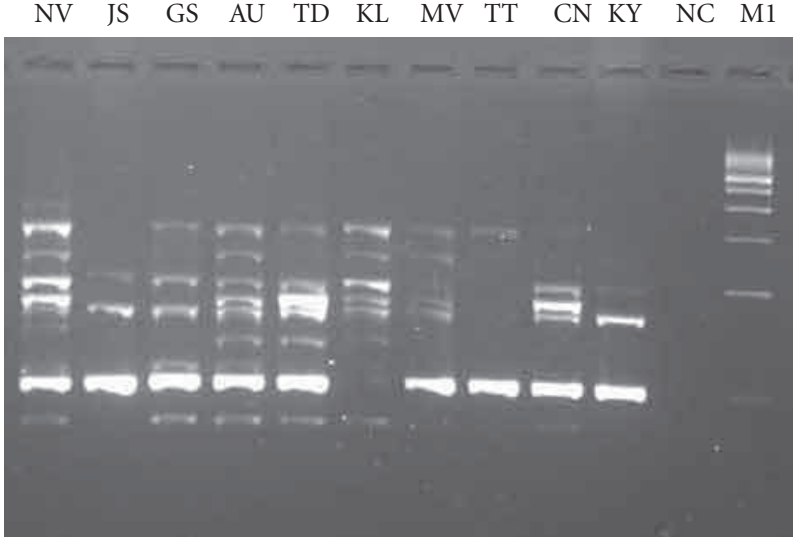

FIgURE 1: Amplicons of the different varieties against the primer OPB-01. NV: Navara; JS: Jeerakasala; GS: Gandhakasala; AU: Adukkan; TD: Thondi; KL: Kanali; MV: Mannuveliyan; TT: Thonnuranthondi; CN: Chennellu; KY: Kalladiyaran; M1: 500 bp marker; M2: 100 bp marker; NC: negative control.

polymorphism, while Thondi and Adukkan showed the lowest $(9.85 \%)$.

Of the different varieties, considering all the primers, Adukkan yielded the highest number of amplicons (78) followed by Kanali (71) (Table 2). Jeerakasala generated the lowest number (56) of bands (Table 2). In cultivarwise, the highest number of DNA bands was observed in Adukkan (12) and was followed by Kanali (11) against the primer OPB-04 (Table 2). The variety Kanali showed 10 amplicons on OPX-04 also (Table 2). The varieties Mannuveliyan, Thondi, and Kalladiyaran produced 10 bands each with OPB-04 (Table 2). Of the different primers, OPAA07 amplified only one DNA band each in the varieties Navara (710 bp) and Mannuveliyan (593 bp). Similarly, the primer OPAB-02 showed only one amplicon each in Navara (853 bp) and Thondi (907bp). The primer OPZ02 showed amplification only in Mannuveliyan ( 2 bands of 1446 and $800 \mathrm{bp}$ ). The primer CB-2 resulted in amplicons only in Thonnuranthondi, Chennellu, and Kalladiyaran (Table 2). The primer OPAB-02 showed no products in the varieties Jeerakasala, Gandhakasala, Mannuveliyan, Thonnuranthondi, and Chennellu. The primers OPM-06 and OPA-02 facilitated no amplicons in Thonnuranthondi, while OPD-08 was without bands in Kalladiyaran. Besides the genetic diversity assessment, RAPD enables distinguishing the varieties without complexity based on the number of amplicons against the primers OPAA-07, OPAB-02, and OPA-02 (Table 2).

In the present study with the primer OPM-06, shown as a marker to tag gall midge resistance [18], the varieties Adukkan, Mannuveliyan, and Chennellu showed a unique band near to $1800 \mathrm{bp}$. Similarly, with the primer OPA-02, reported as a marker to tag blast resistance [19], the varieties Thonnuranthondi and Jeerakasala generated unique bands of sizes $1103 \mathrm{bp}$ and $439 \mathrm{bp}$, respectively.

The similarity matrix obtained using Dice coefficient is shown in Table 3. Similarity coefficient ranged from 0.61 
TABLE 2: Number of amplicons and percent polymorphism in different varieties of rice as to the primers.

\begin{tabular}{|c|c|c|c|c|c|c|c|c|c|c|c|c|}
\hline Primers & $\mathrm{NV}$ & JS & GS & $\mathrm{AU}$ & $\mathrm{TD}$ & $\mathrm{KL}$ & MV & TT & $\mathrm{CN}$ & KY & Total bands & Polymorphism (\%) \\
\hline OPB-01 & 9 & 3 & 6 & 9 & 7 & 6 & 5 & 2 & 5 & 4 & 56 & 100 \\
\hline OPB-04 & 8 & 2 & 3 & 12 & 10 & 11 & 10 & 9 & 9 & 10 & 84 & 100 \\
\hline OPB-20 & 4 & 3 & 5 & 4 & 3 & 3 & 3 & 5 & 4 & 6 & 40 & 50.0 \\
\hline OPA-04 & 4 & 5 & 4 & 5 & 5 & 6 & 4 & 6 & 5 & 5 & 49 & 38.8 \\
\hline OPA-19 & 5 & 8 & 6 & 6 & 3 & 3 & 4 & 4 & 6 & 4 & 49 & 38.8 \\
\hline OPD-16 & 7 & 7 & 8 & 6 & 8 & 7 & 6 & 6 & 6 & 9 & 70 & 42.9 \\
\hline OPX-04 & 5 & 6 & 7 & 9 & 9 & 10 & 8 & 9 & 7 & 5 & 75 & 60.0 \\
\hline OPZ-02 & 0 & 0 & 0 & 0 & 0 & 0 & 2 & 0 & 0 & 0 & 2 & 100 \\
\hline OPAA-07 & 1 & 3 & 2 & 3 & 3 & 4 & 1 & 3 & 3 & 3 & 26 & 100 \\
\hline OPAB-02 & 1 & 0 & 0 & 2 & 1 & 2 & 0 & 0 & 0 & 2 & 8 & 100 \\
\hline OPM-6 & 5 & 3 & 4 & 4 & 4 & 2 & 3 & 0 & 4 & 4 & 33 & 100 \\
\hline OPD-08 & 4 & 5 & 7 & 7 & 5 & 7 & 9 & 9 & 9 & 0 & 62 & 100 \\
\hline OPA-02 & 4 & 3 & 3 & 4 & 4 & 2 & 3 & 0 & 4 & 2 & 29 & 100 \\
\hline CB-1 & 8 & 8 & 8 & 7 & 7 & 8 & 8 & 8 & 3 & 7 & 72 & 58.0 \\
\hline CB-2 & 0 & 0 & 0 & 0 & 0 & 0 & 0 & 3 & 3 & 3 & 9 & 100 \\
\hline Total bands & 65 & 56 & 63 & 78 & 69 & 71 & 66 & 64 & 68 & 64 & 664 & \\
\hline
\end{tabular}

NV: Navara; JS: Jeerakasala; GS: Gandhakasala; AU: Adukkan; TD: Thondi; KL: Kanali; MV: Mannuveliyan; TT: Thonnuranthondi; CN: Chennellu; KY: Kalladiyaran.

(between JS and MV) to 0.90 (between AU and TD) among these 10 varieties.

3.1. Cluster Analysis. The UPGMA cluster analysis using the Dice similarity coefficient confirmed (Figure 2) that the highest value of similarity coefficient was observed between the varieties Adukkan and Thondi, both shared higher level of similarity (0.81), followed by Kanali and Thondi (0.88). Goodness-of-fit analyses suggest that UPGMA is highly useful for the kind of representation, with $r=0.82912$. Of the three subclusters obtained in the dendrogram, the first group associated the varieties of Adukkan, Thondi, Kanali, Mannuveliyan, Thonnuranthondi, and Chennellu with similarity of 0.77 . The second group represented the Navara, Gandhakasala, and Jeerakasala varieties with similarity coefficient of 0.76 and formed a cohesive group. The cultivar Kalladiyaran formed an isolated position that joined the second cluster at the level of 0.70 . The first group consists of scented rice varieties possessing a similarity. Of which, Jeerakasala and Gandhakasala showed more similarity.

3.2. Principal Coordinate Analysis. In $\mathrm{PCO}$ analysis, the first principal coordinate axis accounted for the $24.27 \%$ of total variance, which separated the Kalladiyaran from all the remaining varieties (Figure 3 ). The second coordinate axis included Thonnuranthondi, Chennellu, Adukkan, Mannuveliyan, Kanali, and Thondi varieties with only $17.72 \%$ of the total variation. The varieties representing Kanali, Thondi, Adukkan, and Mannuveliyan form a cohesive structure and found broadly overlapping each other.

\section{Discussion}

Genetic diversity assessment of the traditional rice varieties/landraces is essential to identify potential parents.
Molecular markers, which portray genome sequence composition, enabling detection of differences in the genetic information carried out by the different individuals are highly useful to assess and to utilize the genetic variability for breeding programmes. Unlike the morphological and biochemical markers, molecular markers are not stressed by environmental factors and growth practices [20]. In addition to the identification of correct identity of species, DNA fingerprinting helps to generate molecular database as well as to utilize the information sustainably. RAPD analysis emerged as a routine method for the estimation of genetic diversity and relatedness in plant populations, varieties, and germplasm accessions. Leal et al. [21] could detect more polymorphism through RAPD than that by SSR markers in popcorn. An appraisal of genetic variation, varietal classification, germplasm identification, and domestication process has been accomplished in indica rice varieties [38]. Raghunathachari et al. [8] analysed 18 accessions of Indian scented rice using RAPD. RAPD analysis of the traditional rice varieties in the present study exhibited $72.9 \%$ polymorphism. According to Raghunathachari et al. [8], the extent of polymorphisms depends on the GC content of the primers. They observed $95.1 \%$ polymorphism by the use of primers with 60 to $70 \% \mathrm{GC}$ content. In the present study, the GC content of the primers ranged from 50 to $60 \%$. Increase in the number of bands with increasing GC content of the primers has also been reported in rice [22]. RAPD has been exploited enormously in the evaluation of genetic diversity of other crop plants too: 28 accessions of Crataegus spp. [23] and 12 pomegranate cultivars [24].

RAPD is considered to be elegant and easy for the identification of species, varieties, landraces, accessions, farmers' collections of rice, and so forth, and even somaclonal variations $[4-6,22,25]$. The primers OPAA-07, OPAB-02, and OPA-02 enable identifying all the traditional varieties 
TABLE 3: DICE similarity coefficient (1945) matrix for the rice varieties in the present study.

\begin{tabular}{lcccccccccr}
\hline & NV & GS & JS & AU & TD & KL & MV & TT & CN & KY \\
\hline NV & 1.000 & & & & & & & & & \\
GS & 0.761 & 1.000 & & & & & & & & \\
JS & 0.754 & 0.813 & 1.000 & & & & & & & \\
AU & 0.805 & 0.714 & 0.705 & 1.000 & & & & & \\
TD & 0.785 & 0.687 & 0.661 & 0.899 & 1.000 & & & & \\
KL & 0.750 & 0.666 & 0.671 & 0.866 & 0.879 & 1.000 & & & \\
MV & 0.732 & 0.724 & 0.617 & 0.813 & 0.823 & 0.788 & 1.000 & & \\
TT & 0.630 & 0.619 & 0.622 & 0.736 & 0.770 & 0.808 & 0.748 & 1.000 & \\
CN & 0.691 & 0.682 & 0.624 & 0.816 & 0.811 & 0.748 & 0.761 & 0.796 & 1.000 & \\
KY & 0.676 & 0.619 & 0.573 & 0.694 & 0.711 & 0.705 & 0.671 & 0.707 & 0.721 & 1.000 \\
\hline
\end{tabular}

NV: Navara; JS: Jeerakasala; GS: Gandhakasala; AU: Adukkan; TD: Thondi; KL: Kanali; MV: Mannuveliyan; TT: Thonnuranthondi; CN: Chennellu; KY: Kalladiyaran.

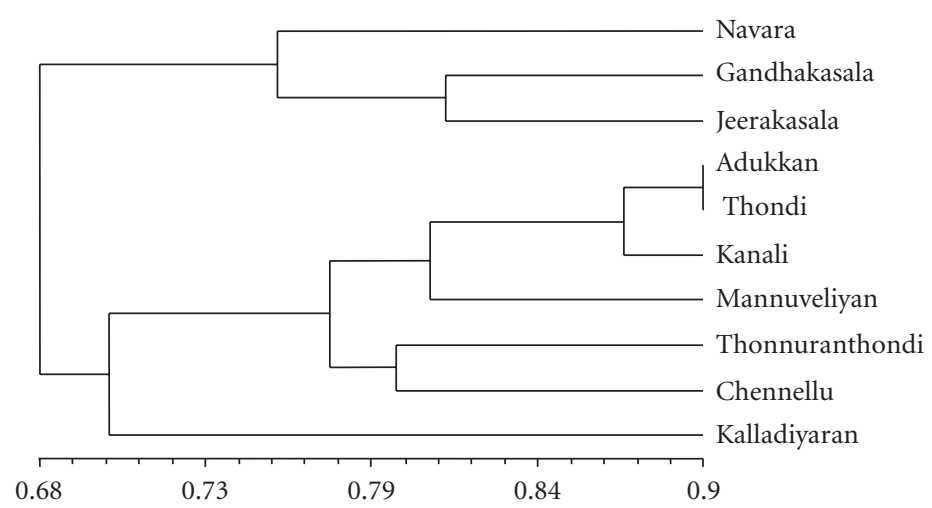

FIGURE 2: UPGMA dendrogram of rice varieties in the present study based on Dice similarity coefficient (1945). The matrix correlation: $r=0.82912$ (= normalized Mantel statistic Z). Approximate Mantel $t$-test: $t=4.4995$. Prob. random $Z<$ obs. $Z: P=1.0000$.

of the present study based on the number of amplicons. Identification of farmers' collections of Kalanamak and traditional varieties of basmati rice has been accomplished [5]. Choudhury et al. [25] documented the identification and classification of aromatic rice based on RAPD fingerprinting.

DNA-based makers serve as powerful tools for discerning variations within crop germplasm and for studying evolutionary relationships [26]. The multivariate analyses of RAPD data obtained from 15 primers using NTSYS in the present study indicated interrelationships among the rice varieties. During the cluster analysis, more closely related varieties identified were Adukkan and Thondi and the distant ones were Kalladiyaran and Jeerakasala. Both UPGMA dendrogram and PCO analysis of varieties indicated the same pattern of interrelationships. Three different groups identified during both these analyses were Thonnuranthondi, Chennellu, Adukkan, Mannuveliyan, Kanali, and Thondi in the first group and Navara, Gandhakasala, and Jeerakasala in the second and Kalladiyaran representing the third. In the present study, the second group consisted of scented rice varieties that possessed similarity. Of which the Jeerakasala and Gandhakasala showed more similarity. The data obtained from the present study can be used for breeding studies and future phylogenetic studies.

RAPD markers are proved to be an efficient tool to tag important genes conferring resistance to abiotic and biotic stresses [10-13, 18, 19, 27, 28]. RAPD marker OPM-06 was identified as being tightly linked to gall midge-resistant gene of Duokang cultivar (18). Similarly, OPA-02 was recognized for the amplification of blast resistance in somaclones from upland rice cultivar IAC 47 [19]. As per Katiyar et al. [18], the presence of a band size $\sim 1400 \mathrm{bp}$ indicates gall midgeresistant gene. In the present study with the primer OPM06, the varieties Adukkan, Mannuveliyan, and Chennellu, which are shown to possess gall midge resistance, produced a unique band near to $\sim 1800 \mathrm{bp}$. The absence of this fragment in other varieties indicates the possibility of this fragment to be the gene linked to gall midge resistance. According to Araújo et al. [19], OPA-02 is characteristic with bands of 1300 and $321 \mathrm{bp}$, which were linked to blast resistance. In the present study, the varieties Thonnuranthondi and Jeerakasala represented unique bands of size $1103 \mathrm{bp}$ and $439 \mathrm{bp}$, respectively. However, in both these cases of resistance, further studies, that is amplification of more samples with these primers along with confirmed gall midge-resistant and blast-resistant varieties and sequencing of the fragments 


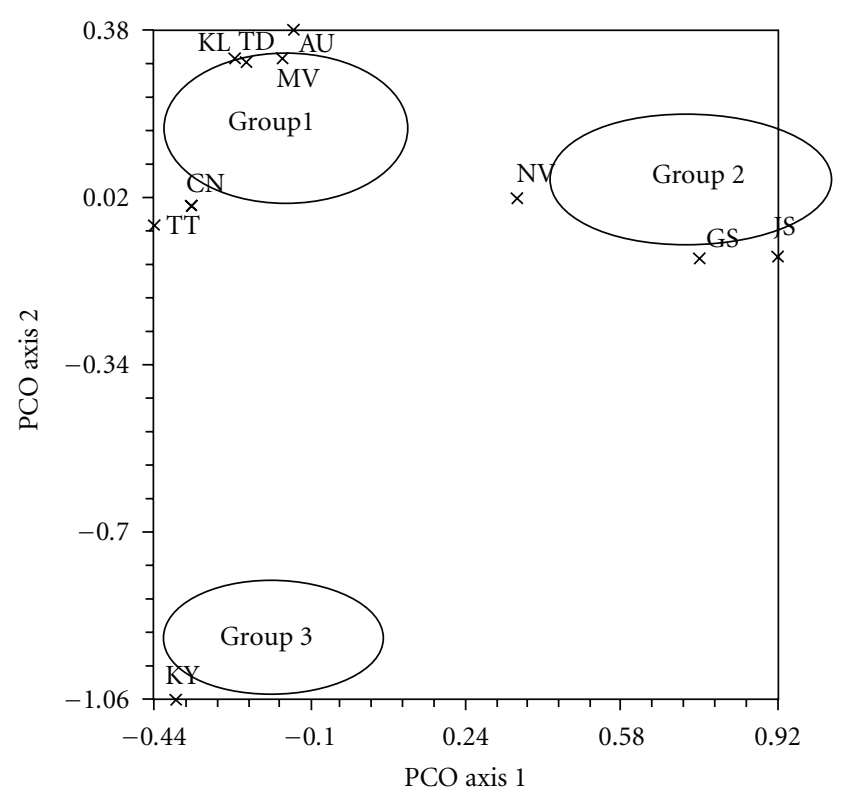

Figure 3: Principal Coordinate Analysis based on RAPD profiles of the rice varieties. Axis 1 extracted $24.27 \%$ of the variation and axis 2 extracted $17.72 \%$ of the variation. NV: Navara; JS: Jeerakasala; GS: Gandhakasala; AU: Adukkan; TD: Thondi; KL: Kanali; MV: Mannuveliyan; TT: Thonnuranthondi; CN: Chennellu; KY: Kalladiyaran.

followed by database search using bioinformatics tools, are to be performed.

RAPD fingerprinting proved to be a worthwhile tool for the genetic relationship and identification of traditional varieties collected from the tribal hamlet of Kerala state, India. Besides, the present study serves as a base enabling the progress further to identify genes conferring resistance to biotic and abiotic genes.

\section{Acknowledgment}

The authors gratefully acknowledge the Department of Biotechnology, Government of India for financial assistance. T. Rekha and K. P. Martin contributed equally to this paper.

\section{References}

[1] Shivkumar, L. V. Subba Rao, T. Ram et al., "Genetic base and coefficient of parentage of rice (Oryza sativa) varieties released in Kerala," Indian Journal of Agricultural Science, vol. 68, no. 1, pp. 1-6, 1998.

[2] D. A. Vaughan, "The wild relatives of rice," in A Genetic Resource Handbook, IRRI, Manila, Philippines, 1994.

[3] P. S. Virk, H. J. Newbury, M. T. Jackson, and B. V. FordLloyd, "The identification of duplicate accessions within a rice germplasm collection using RAPD analysis," Theoretical and Applied Genetics, vol. 90, no. 7-8, pp. 1049-1055, 1995.

[4] U. Masataka, Y. Tooru, T. Yoshimasa, and T. Katsumi, "Identification of variety of glutinous rice by RAPD method," Food Preservation Science, vol. 29, pp. 47-50, 2003.
[5] D. Singh, A. Sirohi, and Vikas, "RAPD based identification of farmers' collections of Kalanamak and traditional varieties of basmati rice," The Indian Journal of Crop Science, vol. 1, pp. 102-105, 2006.

[6] M. A. Rabbani, Z. H. Pervaiz, and M. S. Masood, "Genetic diversity analysis of traditional and improved cultivars of Pakistani rice (Oryza sativa L.) using RAPD markers," Electronic Journal of Biotechnology, vol. 11, no. 3, 2008.

[7] A. P. Davierwala, K. V. Chowdari, S. Kumar, A. P. K. Reddy, P. K. Ranjekar, and V. S. Gupta, "Use of three different marker systems to estimate genetic diversity of Indian elite rice varieties," Genetica, vol. 108, no. 3, pp. 269-284, 2000.

[8] P. Raghunathachari, V. K. Khanna, U. S. Singh, and N. K. Singh, "RAPD analysis of genetic variability in Indian scented rice germplasm (Oryza sativa L.)," Current Science, vol. 79, no. 7, pp. 994-998, 2000.

[9] Z. Anshi, X. Jiuwen, Z. Limin, X. Zhifeng, and W. Huiyan, "RAPD analysis of classification and genetic relationship among Northern japonica rice," Molecular plant breeding, vol. 5, pp. 885-889, 2009.

[10] M. Mohan, S. Nair, J. S. R. Bento, U. P. Rao, and J Bennett, "RFLP and RAPD mapping of the rice gm2 gene that confers resistance to biotype 1 of gall midge (Orseolia oryzae)," Theoretical and Applied Genetics, vol. 87, pp. 782-788, 1994.

[11] S. Yoshimura, A. Yoshimura, R. J. Nelson, T. W. Mew, and N. Iwata, "Tagging Xa-1, the bacterial blight resistance gene in rice, by using RAPD markers," Breeding Science, vol. 45, no. 1, pp. 81-85, 1995.

[12] J. H. Cho, D. Y. Kwak, and K. H. Yi, "Identification and mapping of RAPD markers linked to rice stripe virus resistance gene, $s t v-i$, in rice ( $O$ sativa)," in Proceedings of the 4th International Crop Science, Brisbane, Australia, 2004, http://www.cropscience.org.au/icsc2004/poster/3/4/1/913_ chojh.htm\#TopOfPage.

[13] B. Huang, Y. Zhang, and Z. Xie, "Molecular assisted breeding for resistant varieties against asian rice gall midge in south China," Molecular Plant Breeding, vol. 5, pp. 507-514, 2007.

[14] P. Kumar, S. Pathania, P. Katoch, T. R. Sharma, P. Plaha, and R. Rathour, "Genetic and physical mapping of blast resistance gene $P i-42(t)$ on the short arm of rice chromosome 12," Molecular Breeding, vol. 25, no. 2, pp. 217-228, 2010.

[15] S. L. Dellaporta, J. Wood, and J. B. Hicks, "A plant DNA minipreparation: version II," Plant Molecular Biology Reporter, vol. 1, no. 4, pp. 19-21, 1983.

[16] L. R. Dice, "Measures of the amount of ecologic association between species," Ecology, vol. 26, pp. 297-302, 1945.

[17] P. H. A. Sneath and R. R. Sokal, Numerical Taxonomy, Freeman, San Francisco, Calif, USA, 1973.

[18] S. K. Katiyar, Y. Tan, B. Huang et al., "Molecular mapping of gene $G m-6(t)$ which confers resistance against four biotypes of Asian rice gall midge in China," Theoretical and Applied Genetics, vol. 103, no. 6-7, pp. 953-961, 2001.

[19] L. G. Araújo, A. S. Prabhu, M. C. Filippi, and L. J. Chaves, "Rapd analysis of blast resistant somaclones from upland rice cultivar IAC 47 for genetic divergence," Plant Cell, Tissue and Organ Culture, vol. 67, no. 2, pp. 165-172, 2001.

[20] J. Ovesna, Polakova, and I. Lisova, "DNA analysis and their applications in plant breeding," Czech Journal of Genetics and Plant Breeding, vol. 38, pp. 29-40, 2002.

[21] A. A. Leal, C. A. Mangolin, A. T. Do Amaral et al., "Efficiency of RAPD versus SSR markers for determining genetic diversity among popcorn lines," Genetics and Molecular Research, vol. 9, no. 1, pp. 9-18, 2010. 
[22] S. Fukuoka, K. Hosaka, and O. Kamijima, "Use of random amplified polymorphic DNAs (RAPDs) for identification of rice accessions," Japanese Journal of Genetics, vol. 67, no. 3, pp. 243-252, 1992.

[23] H. Dai, X. Guo, Y. Zhang, Y. Li, L. Chang, and Z. Zhang, "Application of random amplified polymorphic DNA and inter-simple sequence repeat markers in the genus Crataegus," Annals of Applied Biology, vol. 154, no. 2, pp. 175-181, 2009.

[24] N. Hasnaoui, M. Mars, J. Chibani, and M. Trifi, "Molecular polymorphisms in Tunisian pomegranate (Punica granatum L.) as revealed by RAPD fingerprints," Diversity, vol. 2, pp. 107-114, 2010.

[25] P. R. Choudhury, S. Kohli, K. Srinivasan, T. Mohapatra, and R. P. Sharma, "Identification and classification of aromatic rices based on DNA fingerprinting," Euphytica, vol. 118, no. 3, pp. 243-251, 2001.

[26] P. Gepts, "The use of molecular and biochemical markers in crop evolution studies," Evolutionary Biology, vol. 27, pp. 5194, 1993.

[27] S. K. Katiyar, Y. Tan, and X. Zhang, "Identification of RAPD marker linked to the gene controlling gall midge resistance against all biotypes in China," Rice Genetics Newsletter, vol. 1, pp. 128-130, 1994.

[28] S. S. Sandhu, C. Colombo, C. R. Bastos, and W. J. Siqueira, "DNA tagging of blast resistant gene(s) in three Brazilian rice cultivars," Genetics and Molecular Biology, vol. 26, no. 4, pp. 473-476, 2003. 

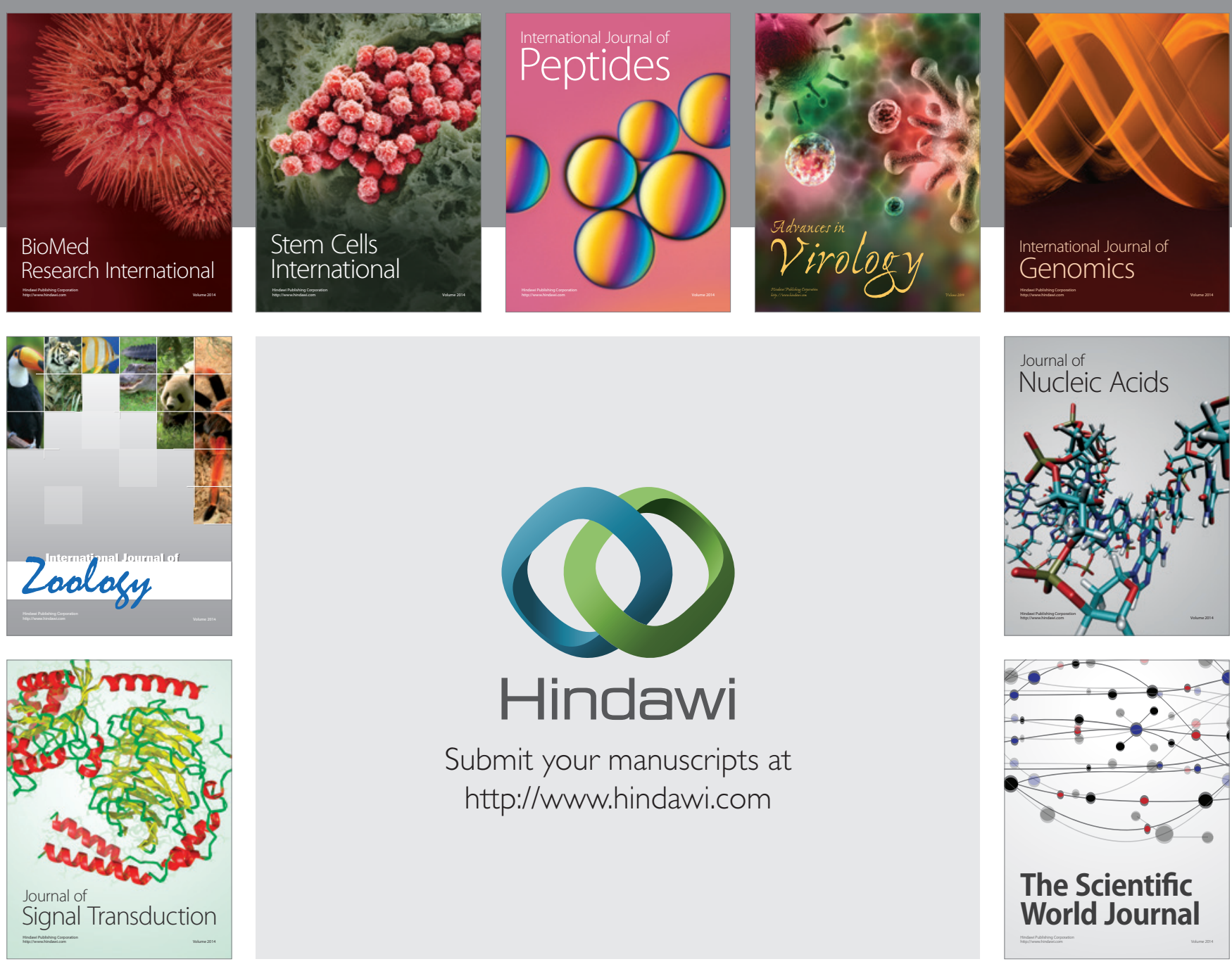

Submit your manuscripts at

http://www.hindawi.com
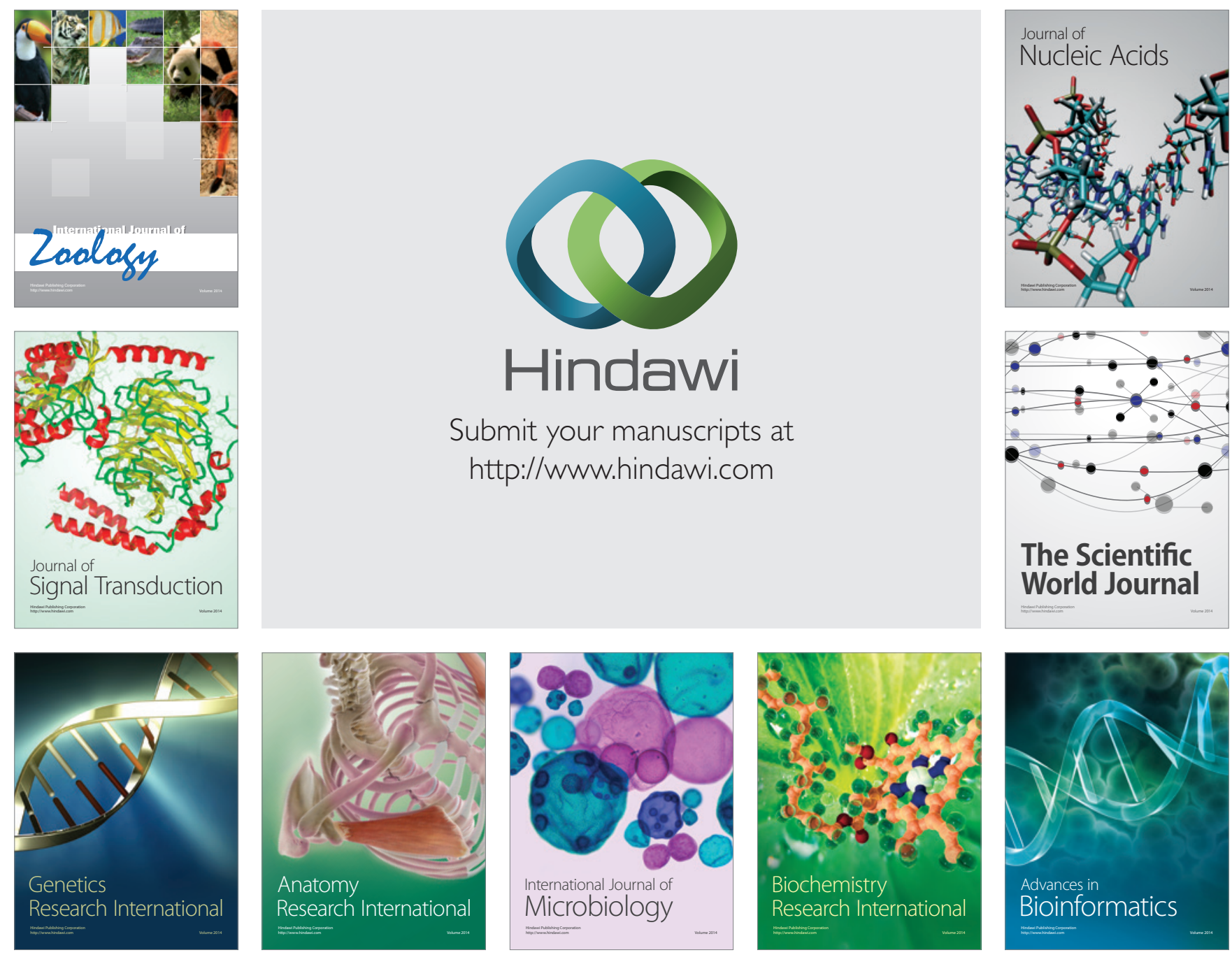

The Scientific World Journal
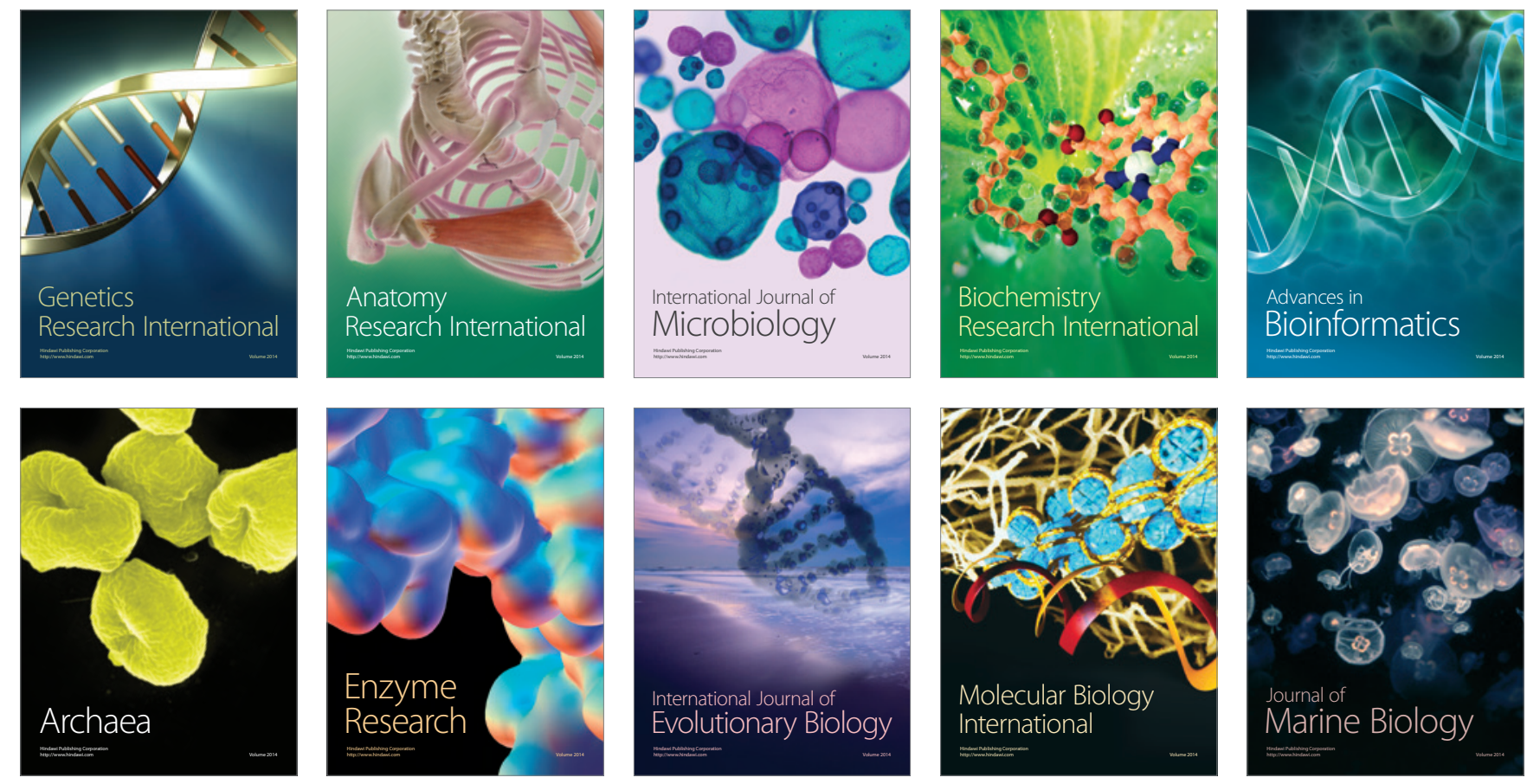